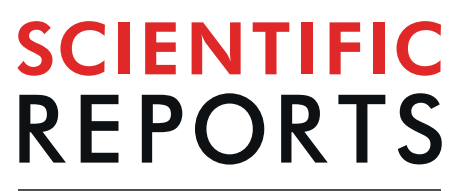

\title{
Relative tail length correlates with body condition in male but not in female crowned leafnose snakes (Lytorhynchus diadema)
}

\author{
Jaim Sivan ${ }^{1}$, Shlomo Hadad ${ }^{2}$, Itay Tesler ${ }^{2}$, Avi Rosenstrauch ${ }^{1}$, Abraham Allan Degen ${ }^{3}$ \& \\ Michael Kam $\mathbb{1}^{3 *}$
}

Reproductive success is the ultimate measure of individual quality; however, it is difficult to determine in free-living animals. Therefore, indirect measures that are related to reproduction are generally employed. In snakes, males typically possess longer tails than females and this sexual size dimorphism in tail length (TL) has generally been attributed to the importance of the tail in mating and reproduction. Thus, intra-sexual differences in tail length, specifically within males, were hypothesized to reflect individual quality. We used a body condition index $(\mathrm{BCl})$ as a measure of quality in snakes and predicted that tail length would be correlated with $\mathrm{BCl}$ in males. We tested our prediction by determining $\mathrm{BCl}$ in the free-ranging adult male and female crowned leafnose snake (Lytorhynchus diadema), a colubrid species that inhabits mainly desert sand dunes. The relative TL was correlated positively and significantly to $\mathrm{BCl}$ in males $\left(\mathrm{F}_{1,131}=11.05 ; \mathrm{r}_{\text {adj }}=0.07 ; P<0.01\right)$ but not in females, thus supporting our prediction. This is the first time that the relationship between TL and body condition was tested in a free-ranging species. In addition, sexual size dimorphism of TL increased intra-specifically with body size, which was also found in interspecific analyses following Rensch's rule.

Sexual size dimorphism (SSD) occurs in many species of invertebrate and vertebrate taxa ${ }^{1,2}$. In general, males are larger than females in bird and mammal species ${ }^{3,4}$, whereas females are larger than males in terrestrial vertebrate ectotherms $s^{5,6}$. According to Rensch's rule, when males are the larger sex, SSD increases with size; ${ }^{1,4}$ however, when females are the larger sex, SSD decreases with size ${ }^{1,7}$. Although these trends seem contradictory, they both reflect greater variance in males than in females ${ }^{8}$. A number of hypotheses have been proposed to explain these evolutionary interspecific trends including sexual selection and mating success, fecundity selection favoring large females, and natural selection for resource partitioning ${ }^{8-11}$.

Sexual size dimorphism has also been observed in lengths of appendages such as in tails. In most snake species, males have relatively longer tails than females. The reason for this difference between sexes was initially explained structurally, as males possess a hemipenis in an elongated pocket at the base of the tail ${ }^{12,13}$. Several hypotheses for the evolution of sexual differences in tail length (TL) have been suggested. Interspecific analyses of tail and body lengths, as well as clutch mass in colubrid snakes, supported both the morphological constraint hypothesis and the female reproductive hypothesis. Consequently, these analyses indicated a male-biased TL dimorphism in taxa having relatively short tails ${ }^{14}$. In addition, the TL was found to be associated with gravitational habitat categories, where terrestrial snake species have shorter tails than arboreal species. This hypothesis was supported in females using 226 snake species in 139 genera and 15 families ${ }^{15}$.

Tails of snakes are important for a number of functions, including locomotion ${ }^{12,15}$, predation ${ }^{16,17}$ and reproduction ${ }^{12,14,18}$. However, a longer tail requires stronger retractor muscles to maneuver ${ }^{14}$ and, therefore, conforms to the power limits hypothesis ${ }^{19}$; that is, males with longer relative TL would be able to use more power over a short time for a successful mating and, consequently, have higher reproductive success.

A characteristic that is advantageous specifically for reproduction for one sex is considered a sexual selected trait. If TL of females is at the optimum size for hunting and locomotion ${ }^{15}$, then the additional length in males

${ }^{1}$ Department of Life Sciences, Achva Academic College, M. P. Shikmim, 79800, Israel. ${ }^{2}$ Negev Zoo, P. O. B, 4033, Beer Sheva, Israel. ${ }^{3}$ Desert Animal Adaptations and Husbandry, Wyler Department of Dryland Agriculture, Institutes for Desert Research, Ben Gurion University of the Negev, Beer Sheva, 8410500, Israel. *email: mkam@bgu.ac.il 


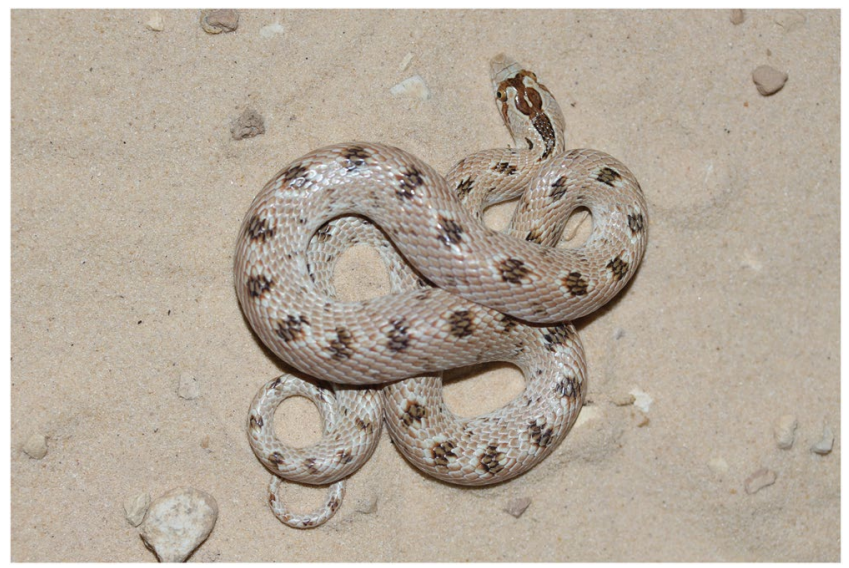

Figure 1. A Lytorhynchus diadema at our research site in the Negev Desert.

should serve a reproductive function, either to house a longer hemipenis or to increase mating opportunities ${ }^{18}$, and could be considered a sexual selected trait ${ }^{20,21}$. Relatively longer tails are advantageous when competing with other male snakes in the process of ball mating ${ }^{18}$ and, consequently, males with longer tails should be more productive $^{18}$ and, thus, should demonstrate higher reproductive success than males with shorter tails. Males that are more successful are, consequently, of better quality. However, although commonly used, the term "individual quality" requires further clarification. Some authors have argued that it should be abandoned ${ }^{22-24}$, while others suggested using a more comprehensive approach such as multivariate analyses of selective traits ${ }^{25}$ or using a better defined term such as "genetic quality" ${ }^{26}$. Darwin ${ }^{27}$, Zahavi $^{28}$ and Emlen et al. ${ }^{21}$, among others, related the term "individual quality" to the reproductive output or fitness of the individual. However, for most animal species, especially when free-ranging, it is not possible to determine individual reproductive success and, consequently, other indirect measures such as body mass, body size or body condition have often been used as individual quality indices/correlators (e.g., Hamel et al. ${ }^{29}$; Peig and $\mathrm{Green}^{30}$ ).

Body condition index (BCI) has been related to reproductive potential and reproductive success ${ }^{31-34}$, and, consequently, fitness of the animal ${ }^{35-37}$. BCI could be estimated using a non-invasive measure that is independent of body size and, in snakes, has been shown to reflect fat reserves ${ }^{38}$. This parameter has been described as being "intimately related to an animal's health, quality or vigour and has been widely claimed to be an important determinant of fitness" ${ }^{30}$. In this study, we used BCI as a measure of individual quality, which we regarded as being related to reproductive success.

We hypothesized that TL is a sexual selective trait where males with relatively longer tails would be of higher individual quality. Using BCI to reflect individual quality, we predicted that males with longer tails would have a higher BCI than males with shorter tails, whereas, no such relationship would exist in females. We also predicted a higher variance of TL in males than in females as sexual characteristics often exhibit higher variability than non-sexual characteristics that are subject to evolutionary stabilizing selection ${ }^{39,40}$. To test our predictions, we determined BCI and TL in the free-ranging adult male and female crowned leafnose snake, Lytorhynchus diadema (Fig. 1). This colubrid species is a terrestrial dweller that possesses sexual dimorphism in both body length and $\mathrm{TL}$ and, therefore, is suitable to test our predictions ${ }^{41}$.

\section{Results}

Average SVL of males $(\mathrm{n}=133), 33.5( \pm 0.31) \mathrm{cm}$, was significantly longer than that of females $(\mathrm{n}=107), 32.0$ $( \pm 0.32) \mathrm{cm}\left(\mathrm{F}_{1,238}=10.12, P<0.01\right)$, the difference amounting to $4.5 \%$; but the variance between sexes was similar $(P=0.348)$. Sexual size dimorphism in SVL was 1.047 and the compressed index was -0.047 . Average TL in males, $5.91( \pm 0.068) \mathrm{cm}$, was significantly longer than in females, $5.28( \pm 0.058)\left(\mathrm{F}_{1,238}=45.61, P<0.001\right)$, the difference amounting to $11.9 \%$, and the variance in TL in males was $72 \%$ higher than in females $(0.62$ vs 0.36 ; $P<0.01)$. Tails of all males and females were intact.

The regression of TL on SVL was significant in males $\left(\mathrm{TL}=0.158 \mathrm{SVL}+0.573 ; \mathrm{r}^{2}=0.48 ; P<0.01\right)$ and in females $\left(\mathrm{TL}=0.118 \mathrm{SVL}+1.512 ; \mathrm{r}^{2}=0.44 ; P<0.01\right)$, and explained more than $40 \%$ of the variation in TL in both sexes (Fig. 2); the slope of the regression equation in males was higher than that of females $\left(\mathrm{S}_{\mathrm{b} 1 \mathrm{-b} 2}=0.0190\right.$; $\mathrm{t}=2.51 ; \mathrm{df}=236 ; P<0.01)$. The proportion of TL to total length was $0.15( \pm 0.012)$ in males and $0.14( \pm 0.012)$ in females and the coefficient of divergence between sexes in TL was 5.5. Tail length dimorphism, based on the difference between sexes in the residuals of $\log \mathrm{TL}$ ( $\mathrm{males}=0.0151$; females $=-0.0153$ ), was 0.0304 . Both size, as $\operatorname{SVL}(\mathrm{t}=14.62 ; P<0.001)$, and $\operatorname{sex}(\mathrm{t}=6.14 ; P<0.001)$ affected $\mathrm{TL}\left(\mathrm{F}_{(2,237)}=150 ; \mathrm{r}^{2}{ }_{\text {adj }}=0.55 ; P<0.001\right)$, and SSD of TL between sexes increased with size (Fig. 2).

BCI did not differ $\left(F_{1,238}=0.381, P=0.538\right)$ between males and females, $11.8( \pm 0.19)$ and $11.6( \pm 0.22)$, respectively. When data on TL from June to August were combined, a significant effect of resTL on BCI was found only in males $\left(\mathrm{F}_{1,131}=11.05 ; \mathrm{r}^{2}\right.$ adj $=0.07 ; P<0.01 ; \mathrm{Fig}$. 3$)$. In males within each month, a significant effect of resTL on BCI was found in July $\left(\mathrm{F}_{1,55}=5.31 ; \mathrm{r}^{2}{ }_{\text {adj }}=0.07 ; P<0.05 ; \mathrm{n}=57\right)$ and in August $\left(\mathrm{F}_{1,16}=15.15 ; \mathrm{r}^{2}\right.$ adj $=0.45$; $P<0.01 ; \mathrm{n}=18)$ but not in June $\left(\mathrm{F}_{1,56}=1.76 ; P=0.19 ; \mathrm{n}=58\right)$, while, in females, no significant effect was found 


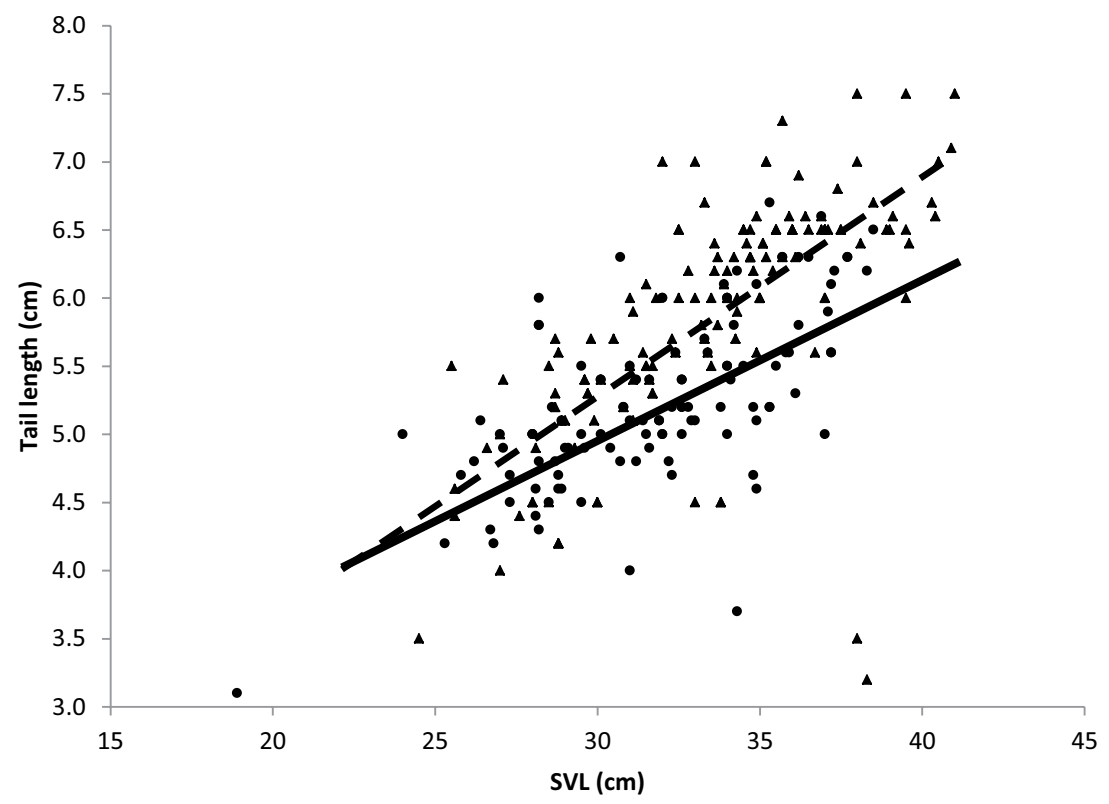

Figure 2. The effect of snout-vent length (SVL) on tail length in male (triangles; dashed line) and female (circles; solid line) Lytorhynchus diadema. The gap between the two regression lines represents the significant increase in sexual dimorphism of tail length with SVL; increase rate of tail length with SVL is higher in males than females (see text for explanation).

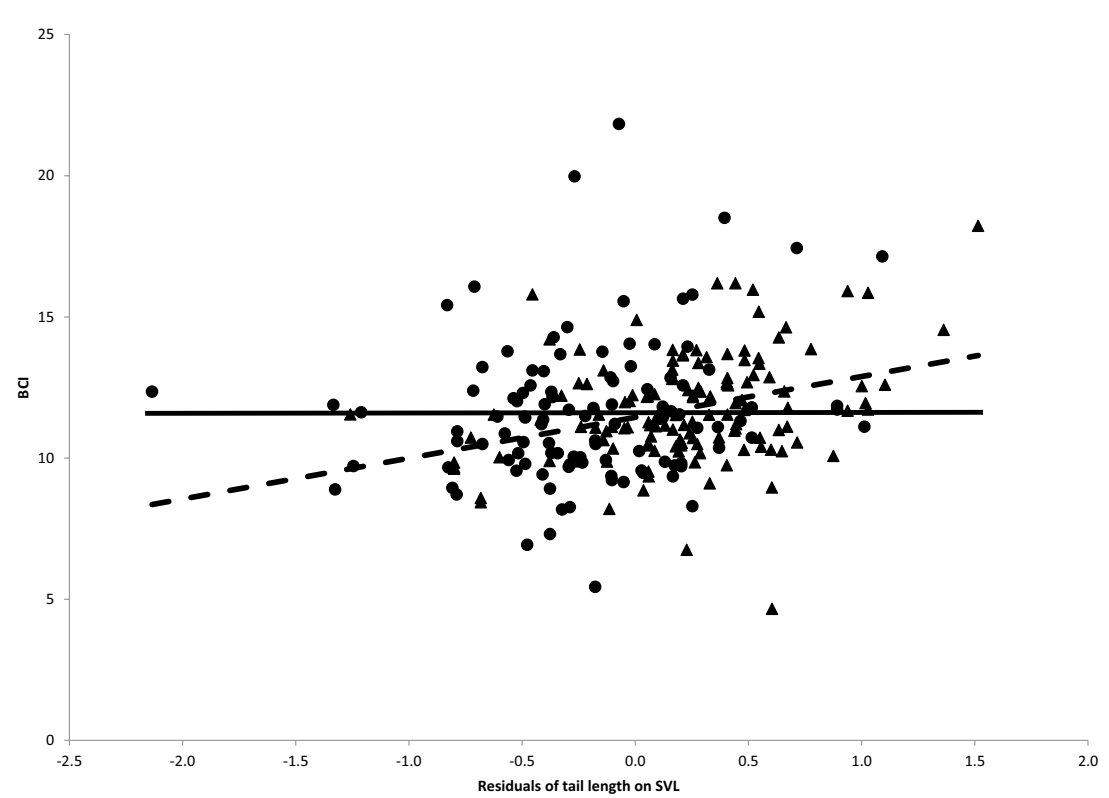

Figure 3. The effect of the residuals of tail length $\left(\mathrm{TL}_{\mathrm{r}}\right)$ on body condition index $(\mathrm{BCI})$ in male (triangles; dashed line; the regression equation took the form of $\mathrm{BCI}=1.01 \mathrm{TL}_{\mathrm{r}}+11.73 ; \mathrm{r}^{2}=0.07 ; P<0.01 ; \mathrm{n}=133$ ) and female (circles and solid line at mean BCI because of non-significant relationship; $P=0.17 ; \mathrm{n}=107$ ) freeranging Lytorhynchus diadema (see text for explanation).

in any of the three months: June $\left(\mathrm{F}_{1,42}=0.80, P=0.38 ; \mathrm{n}=44\right)$, July $\left(\mathrm{F}_{1,47}=1.43, P=0.24 ; \mathrm{n}=49\right)$ and August $\left(\mathrm{F}_{1,12}=0.21, P=0.65 ; \mathrm{n}=14\right)$.

\section{Discussion}

A significant effect of resTL on BCI emerged in males but not in females; consequently, our prediction was supported. The higher variance of TL in males than in females provides further support to our hypothesis that the tail of male L. diadema represents an intra-sexual trait. We questioned how could the non-significant effect for males in June be explained? 
During the mating season, males invest much time in chasing and in mating females but not in feeding, as is common in a number of snake species ${ }^{42}$. Furthermore, in colubrid species, most of the body reserves are mobilized during reproductive activity, in particular in males ${ }^{38,43}$. In June, shortly after mating, male L. diadema were exhausted and that may explain the non-significant effect of resTL on BCI in this month. As the season progressed, males improved their body condition and in August, resTL explained $45 \%$ of the variance in BCI. However, this interpretation should be taken cautiously as BCI varies temporally and can change among years depending on environmental conditions.

Tails as sexual traits in males. Most hypotheses examining TL were tested interspecifically, where a mean value for each species was taken. We are aware of only one intraspecific study in snakes ${ }^{18}$ and, in that study, the hemipenis length of the male garter snake (Thamnophis sirtalis parietalis) was correlated positively with the residuals of TL on snout-vent length (SVL) and, apparently, supported the morphological constraint hypothesis. However, SVL was used to correct only for TL (as residuals), and not for hemipenis length. In addition, this study concluded, albeit indirectly, that the tail was important in mating, as males with a partial tail loss had a lower mating success than males with an intact tail. When males with intact tails were tested, individuals with longer TL had higher mating success, but that "could simply reflect the mating advantage accruing to larger overall body size". When relative TL using residuals of TL on SVL was compared in mated versus unmated males, no difference in relative TL was found ${ }^{18}$.

Based on our findings, we suggest a novel perspective on the length and function of the tail in male $L$. diadema, which could be applicable to other snake species. We found that the residuals of TL on body size in $L$. diadema were significantly and positively correlated with BCI in males but not in females. Interpreting these data from a different perspective, males with longer tails are compensated for the extra energetic cost of supporting their heavier tails; the distance to the regression line (Fig. 3) indicates the relative quality of each snake ${ }^{44}$. Following the handicap hypothesis, an "honest signal" reflects individual quality ${ }^{28,45}$. Longer tails may house longer hemipenes, but that in itself may not be sufficient for successful mating, as was evident for individuals with cut tails ${ }^{18}$. However, longer tails utilize more energy and, during ball mating, require stronger retractor muscles to maneuver and compete successfully with other potential mates. In many cases, handicapped appendages are sexually selected ornaments used by males for display during courtship to attract female mates (see review of $\left(\right.$ Clark $\left.^{19}\right)$. Here, we relate to "handicap" in a broader viewpoint. The tail of male L. diadema is not used for display but rather as an intra-sexual selected trait ${ }^{46}$ or an "intrinsically unfakable index signal" 21 and, indeed, has shown to be more variable in males than females. In addition, compensatory traits are expected to cover the additional costs of the sexual character, tail length in our study, which, in turn, increase the probability of successful mating with a female (e.g. review by Husak and Swallow ${ }^{44}$ ).

Body condition is an important parameter affecting both fecundity and fitness and is a measure of body energy reserves and, hence, differentiates among individuals on the basis of their quality. Here, and for the first time, we propose an intraspecific link between a specific characteristic and individual quality in free-ranging snakes. Furthermore, we were able to statistically explain much of the variance in TL and suggest consequences of individual quality.

Sexual dimorphism. In most snake species, females are longer (in SVL) than males and in 56 colubrid genera, $73 \%$ conformed to this $\mathrm{SSD}^{14}$. Within the group of longer males than females, SSD ranged between 1.010 in Cyclocorus and 1.498 in Drymoluber ${ }^{14}$. In snakes, body size of the female is related with its reproductive effort and, consequently, with mode of reproduction. The "female reproductive output hypothesis" implies that SSD should be more female-biased in oviparous taxa than in viviparous taxa ${ }^{14}$. Interestingly, all 15 colubrid genera with longer males than females were oviparous. L. diadema fell within this minority group with a SVL dimorphism of 1.047. Furthermore, females within this group exhibited relatively longer tails than males except for one genus, Cyclocorus, with a TLD of 0.029 , which was similar to the 0.030 of L. diadema. Within oviparous colubrids, females had relatively longer tails than males in more than $70 \%$ ( 29 of 41 ) of the genera (calculated from King ${ }^{14}$ ).

The proportion of TL to total length of adult L. diadema females $(0.14 \pm 0.012)$ was similar to the average for 49 non-scansorial colubrid female snakes ${ }^{15}(0.17 \pm 0.060)$ and was substantially lower than the average for arboreal colubrid female snakes $(0.31 \pm 0.073)$. Consequently, the sexual dimorphism in TL was higher than that of arboreal colubrid snake species. The coefficient of divergence in TL of 5.5 in L. diadema was at the lower end of the range for 49 colubrid snakes ${ }^{13}$. However, the TL dimorphism index, which is a more balanced index and independent of body size, was higher in L. diadema than that of many other colubrid snake species ${ }^{14}$, and fell in the upper $25 \%$ of values. We conclude that the high TL dimorphism index in L. diadema reflects the importance of the male TL for successful mating.

Consequences of rensch's rule. Rensch's rule states that SSD typically increases with body size in interspecific comparisons when males are the larger sex. There have been a number of hypotheses explaining this generally accepted evolutionary trend in animals $s^{8,11,47,48}$, including in snakes ${ }^{10,49,50}$. It was also stated that males would exhibit greater variance in size than females ${ }^{8}$. In L. diadema, the male is the larger sex and the variance in TL was higher than that in the female. Our study design allowed testing whether evolutionary perspectives of Rensch's rule can be applied intra-specifically as well as interspecifically for sexual dimorphism in TL. Our analysis indicated that it can, as SSD of TL between sexes increased with body size. It would be interesting to examine similar intraspecific relationships across various colubrid species and other taxa to test whether these findings reflect a general trend. 


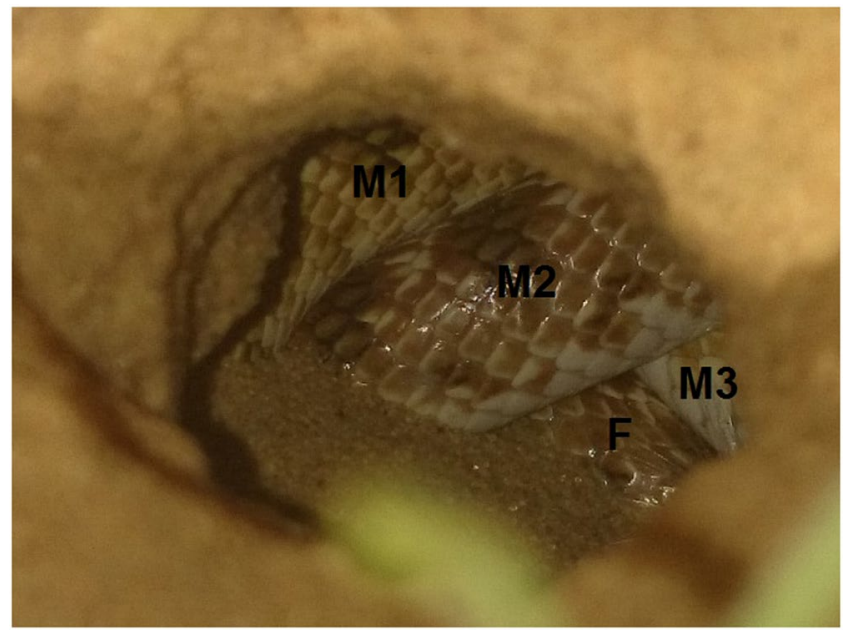

Figure 4. Three Lytorhynchus diadema males (M1, M2, M3) coiled around a female (F) at the entrance of a rodent burrow in a 'mating ball'. L. diadema vary in color allowing the distinction among individuals.

\section{Methods}

Snake species and study site. The crowned leafnose (Lytorhynchus diadema) inhabits mainly desert dunes ranging from the Atlantic coast to the Red Sea in North Africa, northward to the Mediterranean coast and eastward to the Arava (part of the Rift Valley). It also occurs allopathically in other deserts and along the Mediterranean coast of Israel ${ }^{51}$. This colubrid species is active from April to October and is not active in winter ${ }^{52}$. It is a nocturnal hunter consuming primarily small lizards and lizard eggs ${ }^{52}$. Mating occurs in April - May ${ }^{53}$ when "mating balls" are formed. In this reproductive process, several males are coiled around a female (Fig. 4), as has been documented in other colubrid snakes ${ }^{18}$. Females lay 3-5 eggs in the sand in June - July ${ }^{53}$ and young hatch synchronously in August ${ }^{41}$. During the current study, we observed three events of egg laying, all in late June. The three females were not handled due to nature protection restrictions and, therefore, were not included in the analyses.

The study was undertaken in the desert sand dunes surrounding Wadi Seher, situated in the western Negev, Israel, $15 \mathrm{~km}$ south of Beer-Sheva $\left(31^{\circ} 5.4^{\prime} \mathrm{N}\right.$ and $\left.34^{\circ} 48.6^{\prime} \mathrm{E}\right)$, at 320 to $340 \mathrm{~m}$ above sea level. Annual rainfall at the site averages $150 \mathrm{~mm}$, and is characterized by high annual variations and in temporal and spatial distribution. All rainfall occurs in winter from November to March with 60\% generally falling in December and January, and, consequently, other than dew, no surface water was available to the snakes during the entire study. Winters are mild; the coldest month, January, has mean minimum and maximum air temperatures of $7.6^{\circ} \mathrm{C}$ and $18.1^{\circ} \mathrm{C}$, respectively. Summers are hot and dry lasting from June to October. The hottest month, August, has mean minimum and maximum air temperatures of $20.2^{\circ} \mathrm{C}$ and $33.5^{\circ} \mathrm{C}$, respectively ${ }^{54}$. The dominant vegetation is of the Saharo-Arabian type with the main plants consisting of Artemisia monosperma, Stipagrostis scoparia, Convolvulus lanatus, Retama raetam, Stipa capersis, Hammada scoparia, Neurada procumbes and Noaea mucronata.

Capture and measurements. Random scans of the area were made on foot from dawn to dusk to identify the typical lateral weaving serpentine tracks of $L$. diadem $a^{41,52}$. Tracks were followed and the snakes were captured by hand. The sex of the snake was based on the distinct difference between males and females in the depth of the sub-caudal pocket ${ }^{55,56}$. A reptile sexing probe was inserted gently into the cloaca towards the tip of the tail to determine the number of sub-caudals; females measured 1-3 whereas males measured $>4$. Snakes were weighed to the nearest $0.01 \mathrm{~g}$ (Ohaus Balance, Model CT 200) and SVL and TL were measured to the nearest $0.1 \mathrm{~cm}$ using a measuring tape after securing the snake gently on a board. To minimize errors, two researchers (JS and SH) made all measurements. Snakes were handled for less than $5 \mathrm{~min}$ to complete the measurements and then were released at the place of capture. On the bases of SVL and month of capture, L. diadema were classified as neonates, juveniles and adults ${ }^{41}$; only adults were included in this study. Re-capture of the same individual at the study site is low; based on marked individuals at the same site in a previous study, less than $5 \%$ were re-captured within the same month (unpublished data). Hence, for statistical analyses, each measurement was considered independent. Data were collected over 5 years on 162 nights in June, July and August when no rain fell and, in total, 133 males and 107 females were used in the analyses (Supplementary Table 1). All procedures on the snakes were approved by the Israel Nature and National Parks Protection Authority and the Ben-Gurion University Committee for the Ethical Care and Use of Animals in Experiments. All methods were carried out in accordance with relevant guidelines and regulations.

Body condition index and sexual dimorphism. In snakes, BCI is commonly estimated from the residuals of the ordinary least squares (OLS) intraspecific regression of body mass on SVL ${ }^{35,36,57,58}$, where SVL is taken as the measure of body size $\mathrm{e}^{59}$. Using this method, approximately $50 \%$ of the variation in BCI was found to be due to variation in fat bodies, which allowed this method to test for differences in body condition statistically ${ }^{60}$. In a laboratory study, when BCI was corrected for ingesta (or recent feed intake), there was little difference in the estimation of fat, which implied that BCI can be measured in free-living snakes "without having to allow the snakes 
to clear their digestive tracts" ${ }^{60}$. To estimate BCI in the present study, we used the "scaled mass index", which has been shown to be even a better predictor of variations in fat and protein reserves than the OLS residual method and five other methods ${ }^{30,61}$. Briefly, this index is based on the reduced major axis (RMA) method for calculating a structural relationship ${ }^{62}$. The RMA method, which is appropriate for our study species (see Smith ${ }^{63}$ ), allows errors in both variables and both are not affected by scale transformations. Controversy has arisen recently regarding whether RMA or OLS regression is most appropriate for studies of allometry and scaling, and OLS was suggested as a preferred statistical method (e.g. Kilmer and Rodríguez ${ }^{64}$ ). However, for calculating BCI, the aim of the regression is not to predict the body mass of a non-measured individual given its SVL, but to estimate the scaling exponent between two interdependent variables ${ }^{50,65}$. Further support and a thorough review, justification and validation of this method were presented by Peig and $\mathrm{Green}^{61}$; calculation of the BCI of free-ranging L. diadema ${ }^{41}$ followed their scaled mass index. Neither surface water nor rainfall was available at the study site when the snakes were active. However, dew was available and, therefore, dehydration should not have been a factor in using BCI as a measure of body condition in this study.

Sexual size dimorphism was calculated following Lovich and Gibbons ${ }^{66}$ ("compressed" SDI) as [SVL of the larger sex/SVL of the smaller sex minus 1]; by convention, negative when males are the larger sex and positive when females are the larger sex. In this index, values are symmetric around zero. To allow for comparison with other snake species, we also present sexual dimorphism in snout-vent length (SVLD) following King ${ }^{14}$. Dimorphism in tail length (TLD) was calculated from the regression of TL on SVL as the difference in mean residual TL between sexes ${ }^{14}$. The data underwent log transformations to allow for interspecific comparisons ${ }^{14}$ and the "coefficient of divergence" in tail length between sexes was calculated to allow for comparison with the data of Clark ${ }^{13}$.

Statistics. To remove the effect of SVL (size) on TL and to allow for comparisons among different sized individuals, residual TL (resTL) was calculated separately for each $\operatorname{sex}^{14}$. A t-test was used to test for differences in SVL, TL and BCI between sexes, and the Levene test was used to test for differences in variance. To examine the effect of SSD of TL on SVL intra-specifically, an ANCOVA was used to test for difference between the two regression estimates of TL on SVL in males and females. Measurements are presented as means $( \pm \mathrm{SE})$ and $P<0.05$ was accepted as the level of significance. Statistica 7 (Stat Soft Inc., Tulsa, OK, USA) was used for statistical analyses.

Received: 25 October 2019; Accepted: 24 February 2020;

Published online: 05 March 2020

\section{References}

1. Rensch, B. Evolution Above the Species Level (Columbia University Press, New York 1959).

2. Shine, R. The evolution of large body size in females: a critique of Darwin's "fecundity advantage" model. Am. Nat. 131, 124-131 (1988).

3. Selander, R. K. Sexual selection and dimorphism in birds in Sexual Selection and the Descent of Man, 1871-1971 (ed. Campbell, B. G.) 180-230 (Aldine, Chicago 1972).

4. Ralls, K. Sexual dimorphism in mammals: avian models and unanswered questions. Am. Nat. 111, 917-938 (1977).

5. Ghiselin, M. T. The Economy of Nature and the Evolution of Sex (University of California Press, Berkeley 1974).

6. Shine, R. Sexual selection and sexual dimorphism in the Amphibia. Copeia 1979, 297-306 (1979).

7. Fairbairn, D. J. Correlated traits for migration in the Gerridae (Hemiptera, Heteroptera): a field test. Ecol. Entomol. 15, 131-142 (1990).

8. Fairbairn, D. J. \& Preziosi, R. F. Sexual selection and the evolution of allometry for sexual size dimorphism in the water strider, Aquarius remiges. Am. Nat. 144, 101-118 (1994).

9. Shine, R. Ecological causes for the evolution of sexual dimorpism: a review of the evidence. Quart. Rev. Biol. 64, 419-461 (1989).

10. Cox, R. M., Butler, M. A. \& John-Alder, H. B. The evolution of sexual size dimorphism in reptiles in Sex, size and Gender Roles: evolutionary Studies of Sexual Size Dimorphism (eds. Fairbairn, D. J. Blanckenhorn, W. U. \& Szekdy, T.) 38-49 (Oxford University Press 2007).

11. Hirst, A. G. \& Kiørboe, T. Macroevolutionary patterns of sexual size dimorphism in copepods. Proc. Roy. Soc. B 281, 20140739 (2014).

12. Klauber, L. M. Tail-length differences in snakes with notes on sexual dimorphism and the coefficient of divergence. Bull. Zool. Soc. San. Diego. 18, 1-60 (1943).

13. Clark, D. R. Jr. Notes on sexual dimorphism in tail-length in American snakes. Trans. Kans. Acad. Sci. 69, 226-232 (1966).

14. King, R. B. Sexual dimorphism in snake tail length: sexual selection, natural selection, or morphological constraint? Biol. J. Linn. Soc. 38, 133-154 (1989).

15. Sheehy, C. M. III, Albert, J. S. \& Lillywhite, H. B. The evolution of tail length in snakes associated with different gravitational environments. Funct. Ecol. 30, 244-254 (2016).

16. Heatwole, H. \& Davison, E. A review of caudal luring in snakes with notes on its occurrence in the Saharan sand viper, Cerastes vipera. Herpetol. 32, 332-336 (1976).

17. Rabatsky, A. M. Caudal luring as a precursor in the evolution of the rattle: a test using an ancestral rattlesnake, Sisturus miliarius barbouri in The Biology of Rattlesnakes (eds. Hayes, W. K., Beaman, K.R., Cardwell, M. D., \& Bush, S. P.) $143-154$ (Loma Linda University Press, Loma Linda 2008).

18. Shine, R., Olsson, M. M., Moore, I. T., LeMaster, M. P. \& Mason, R. T. Why do male snakes have longer tails than females? Proc. Roy. Soc. B 266, 2147-2151 (1999).

19. Clark, C. J. The role of power versus energy in courtship: what is the "energetic cost" of a courtship display? Anim. Behav. 84, 269-277 (2012)

20. Darwin, C. On the Origin of Species by Means of Natural Selection (John Murray, London 1859).

21. Emlen, D. J., Warren, I. A., Johns, A., Dworkin, I. \& Lavine, L. C. A mechanism of extreme growth and reliable signaling in sexually selected ornaments and weapons. Science 337, 860-864 (2012).

22. Wilson, A. J. \& Nussey, N. H. What is individual quality? An evolutionary perspective. TREE 25, 207-214 (2010).

23. Lailvaux, S. P. \& Kasumovic, M. M. Defining individual quality over lifetimes and selective contexts. Proc. Roy. Soc. B 278, 321-328 (2011).

24. McGuigan, K., Rowe, L. \& Blows, M. W. Pleiotropy, apparent stabilizing selection and uncovering fitness optima. TREE 26, 22-29 (2011). 
25. Hamel, S., Gaillard, J. M., Festa-Bianchet, M. \& Côté, S. D. Individual quality, early life conditions, and reproductive success in contrasted populations of large herbivores. Ecology 90, 1981-1995 (2009).

26. Hunt, J., Bussiere, L. F., Jennions, M. D. \& Brooks, R. What is genetic quality? TREE 19, 329-333 (2004).

27. Darwin, C. The Descent of Man and Selection in Relation to Sex (Random House, Modern Library, New York 1871).

28. Zahavi, A. Cost of honesty (further remarks on the handicap principle). J. Theoret. Biol. 67, 603-5 (1977).

29. Hamel, S., Côté, S. D., Gaillard, J. M. \& Festa-Bianchet, M. Individual variation in reproductive costs of reproduction: high quality females always do better. J. Anim. Ecol. 78, 143-151 (2009).

30. Peig, J. \& Green, A. J. The paradigm of body condition: a critical reappraisal of current methods based on mass and length. Funct. Ecol. 24, 1323-1332 (2010)

31. Aubret, F., Bonnet, X., Shine, R. \& Lourdais, O. Fat is sexy for females but not males: The influence of body reserves on reproduction in snakes (Vipera aspis). Horm. Behav. 42, 135-147 (2002).

32. Catherine, A. D., LeMaster, M. P. \& Lutterschmidt, D. I. Physiological correlates of reproductive decisions: relationships among body condition, reproductive status, and the hypothalamus-pituitary-adrenal axis in a reptile. Horm. Behav. 100, 1-11 (2018).

33. Lind, C. M. \& Beaupre, S. J. Male snakes allocate time and energy according to individual energetic status: body condition, steroid hormones, and reproductive behavior in timber rattlesnakes, Crotalus horridus. Physiol. Biochem. Zool. 88, 624-633 (2015).

34. Milenkaya, O., Catlin, D. H., Legge, S. \& Walters, J. R. Body condition indices predict reproductive success but not survival in a sedentary, tropical bird. PLOS ONE 10, e0136582 (2015).

35. Schulte-Hostedde, A. I., Zinner, B., Millar, J. S. \& Hickling, G. J. Restitution of mass-size residuals: validating body condition indices. Ecology 86, 155-163 (2005)

36. Waye, H. L. \& Mason, R. T. A combination of body condition measurements is more informative than conventional condition indices: Temporal variation in body condition and testosterone in brown tree snakes (Boiga irregularis). Gen. Comp. Endocrinol. 155, 607-612 (2008)

37. Valencia-Flores, E., Venegas-Barrera, C. S., Fajardo, V. \& Manjarrez, J. Microgeographic variation in body condition of three Mexican garter snakes in central Mexico. PeerJ. 7, e6601 (2019).

38. Bonnet, X. \& Naulleau, G. Are body reserves important for reproduction in male Dark Green Snakes (Colubridae: Coluber viridiflavus)? Herpetologica 52, 137-146 (1996).

39. Andersson, M. Sexual Selection (New Jersey: Princeton University Press 1994).

40. Pomiankowski, A. \& Moller, A. P. A resolution of the lek paradox. Proc. Roy. Soc. B 260, 21-29 (1995).

41. Sivan, J. et al. Body size and seasonal body condition in two small coexisting desert snake species, the Saharan sand viper (Cerastes vipera) and the crowned leafnose (Lytorhynchus diadema). J. Arid Environm. 114, 8-13 (2015).

42. Shine, R. Reproductive strategies in snakes. Proc. Roy. Soc. B 270, 995-1004 (2003).

43. Shine, R. \& Mason, R. Do a male garter snake’s energy stores limit his reproductive effort? Can. J. Zool. 83, 1265-1270 (2005).

44. Husak, J. F. \& Swallow, J. G. Compensatory traits and the evolution of mate ornaments. Behaviour 148, 1-29 (2011).

45. Zahavi, A. \& Zahavi, A. The Handicap Principle: A Missing Piece of Darwin's Puzzle (Oxford University Press 1997).

46. Oufiero, C. E. \& Garland, T. Jr. Evaluating performance costs of sexually selected traits. Funct. Ecol. 21, 676-689 (2007).

47. Blanckenhorn, W. U. et al. Proximate causes of Rensch's rule: does sexual size dimorphism in arthropods result from sex differences in development time? Am. Nat. 169, 245-257 (2007).

48. Reiss, M. J. Sexual dimorphism in body size: are larger species more dimorphic? J. Theoret. Biol. 121, 163-172 (1986).

49. Abouheif, E. \& Fairbairn, D. J. A comparative analysis of allometry for sexual size dimorphism: assessing Rensch's rule. Am. Nat. 149, 540-562 (1997).

50. Fairbairn, D. J. Allometry for sexual size dimorphism: pattern and process in the coevolution of body size in males and females. Ann. Rev. Ecol. Systemat. 28, 659-87 (1997).

51. Werner, Y. L. Survey of Israel (1950-85) with comments on Sinai and Jordan and on zoogeographical heterogeneity in The Zoogeography of Israel (eds. Yom-Tov, Y. \& Tchernov, E.) 355-388 (Junk Publishers, Dordrecht, Netherlands 1988).

52. Sivan, J. et al. Temporal activity and dietary selection in two coexisting desert snakes, the Saharan sand viper (Cerastes vipera) and the crowned leafnose (Lytorhynchus diadema). Zoology 116, 113-117 (2013).

53. Werner, Y. L. Reptile Life in the Land of Israel (Chimaira, Frankfurt, Germany 2016).

54. Goldreich, Y. The Climate of Israel (Kluwer, New York 2003).

55. Lazlo, J. Probing as a practical method of sex recognition in snakes. Int. Zoo Year. 15, 178-179 (1975).

56. Marais, J. Probing and marking snakes. J. Herpetol. Assoc. Africa 30, 15-16 (1984).

57. Moore, I. T., Lerner, J. P., Lerner, D. T. \& Mason, R. T. Relationships between annual cycles of testosterone, corticosterone, and body condition in male red-spotted garter snakes, Thamnophis sirtalis concinnus. Physiol. Biochem. Zool. 73, 307-312 (2000).

58. Green, A. J. Mass/length residuals: measures of body condition or generators of spurious results? Ecology 82, 1473-1483 (2001).

59. Bonnet, X., Shine, R., Naulleau, G. \& Vacher-Vallas, M. Sexual dimorphism in snakes: different reproductive roles favour different body plans. Proc. of Roy. Soc. B 265, 179-183 (1998).

60. Weatherhead, P. J. \& Brown, T. Measurement versus estimation of condition in snakes. Can. J. Zool. 74, 1617-1621 (1996).

61. Peig, J. \& Green, A. J. New perspectives for estimating body condition from mass/length data: the scaled mass index as an alternative method. Oikos 118, 1883-1891 (2009).

62. McArdle, B. H. The structural relationship: regression in biology. Canadian J. Zool. 66, 2329-2339 (1988).

63. Smith, R. J. Use and misuse of the reduced major axis for line-fitting. Am. J. Phys. Anthropol. 140, 476-486 (2009).

64. Kilmer, J. T. \& Rodriguez, R. L. Ordinary least squares regression is indicated for studies of allometry. J. Evolut. Biol. 30, 4-12 (2017).

65. LaBarbera, M. Analyzing body size as a factor in ecology and evolution. Ann. Rev. Ecol. Syst. 20, 97-117 (1989).

66. Lovich, J. E. \& Gibbons, J. W. A review of techniques for quantifying sexual size dimorphism. Growth Develop. Aging 56, 269-281 (1992).

\section{Acknowledgements}

We thank two anonymous reviewers and Ido Tsurim for helpful suggestions. Tracking of animals and experimental procedures were done with permission from the Israel Nature and National Parks Protection Authority.

\section{Author contributions}

All authors conceived and designed the experiments; J.S., S.H. and I.T. collected the data; J.S., A.A.D. and M.K. analyzed the data and wrote the manuscript.

\section{Competing interests}

The authors declare no competing interests. 


\section{Additional information}

Supplementary information is available for this paper at https://doi.org/10.1038/s41598-020-61168-y.

Correspondence and requests for materials should be addressed to M.K.

Reprints and permissions information is available at www.nature.com/reprints.

Publisher's note Springer Nature remains neutral with regard to jurisdictional claims in published maps and institutional affiliations.

(c) (i) Open Access This article is licensed under a Creative Commons Attribution 4.0 International License, which permits use, sharing, adaptation, distribution and reproduction in any medium or format, as long as you give appropriate credit to the original author(s) and the source, provide a link to the Creative Commons license, and indicate if changes were made. The images or other third party material in this article are included in the article's Creative Commons license, unless indicated otherwise in a credit line to the material. If material is not included in the article's Creative Commons license and your intended use is not permitted by statutory regulation or exceeds the permitted use, you will need to obtain permission directly from the copyright holder. To view a copy of this license, visit http://creativecommons.org/licenses/by/4.0/.

(C) The Author(s) 2020 